\title{
Teaching E-Business Concepts Using SAP's OnLine Store
}

\author{
Paul Hawking \\ Victoria University, \\ Melbourne, Australia
}

Paul.Hawking@vu.edu.au

\author{
Brendan McCarthy \\ Victoria University, \\ Melbourne, Australia
}

Brent

dan.McCarthy@vu.edu.au

\author{
Susan Foster \\ UNITEC, Auckland, \\ New Zealand
}

Susanfos-

er@optusnet.com.au

\begin{abstract}
Many universities around the world have formed strategic alliances with Enterprise Resource Planning (ERP) systems vendors to incorporate these types of systems into their curriculum. Over the past few years the sharing of curriculum resources between universities has facilitated this process. Universities are now struggling with the concept of how to develop e-business curriculum incorporating their existing ERP system. Universities are faced with firstly having to implement the available functionality and then develop the appropriate curriculum. This paper describes a student centric method to assist universities with this curriculum delivery. Students at Victoria University have implemented and documented the implementation process of SAP's OnLine Store. This documentation will be freely distributed to other universities to assist them with their implementation. Staff at the University are in the process of developing e-business curriculum based on the OnLine Store which will also be distributed to other universities.
\end{abstract}

Keywords: Enterprise Resource Planning Systems, SAP, e-business, IS curriculum, OnLine Store.

\section{Introduction}

Since its inception the Information Systems (IS) discipline has become an essential component in the employment of information technology personnel in business and government organisations. Information technology has undergone rapid and continuous change in recent times and accordingly university's IS curriculum has evolved to keep pace with this change. The function of IS now, is one of supporting innovation, planning and coordinating resources and systems, rather than one where specialists work in isolation. It has moved from processing data to providing an information infrastructure with applications aligned to organisational strategy (Longenecker and Feinstein, 1994) Although it is not possible to obtain universal agreement on the exact components, Information Systems is oriented towards business, involving the matching of information systems' requirements to an organisation's objectives. IS professionals, to be effective, require formal technical training and a '... sound educational foundation in their discipline so they can keep abreast of new technologies and be responsive to change' (Richards and Sanford, 1992 ). However there is agreement on the generic characteristics which permeate the IS discipline:

- IS professionals must have a broad business and real world perspective.

- IS professionals must have strong analytical and critical thinking skills and

- IS professionals must have strong interpersonal communication and team skills (Davis et al, 2001).

Material published as part of these proceedings, either on-line or in print, is copyrighted by Informing Science. Permission to make digital or paper copy of part or all of these works for personal or classroom use is granted without fee provided that the copies are not made or distributed for profit or commercial advantage AND that copies 1) bear this notice in full and 2) give the full citation on the first page. It is permissible to abstract these works so long as credit is given. To copy in all other cases or to republish or to post on a server or to redistribute to lists requires specific permission from the publisher at Pubtistee@intormingscience.org.
In recent times there has been varying levels of panic as IS professionals consider how to incorporate aspects of the internet and electronic commerce into IS curriculum. Initially, a plethora of new subjects were proposed that were basically existing subjects with "e-" preceding the subject name. It 
was felt that many universities did this to gain a competitive advantage through the "first mover" principal. As academics began to grasp many of the new concepts of the e-world and their implications, the use of the term e-commerce was slowly replaced by the term e-business. E-business differs from e-commerce in that it relies on the integration of business processes and the supporting technologies to gain competitive advantage across the extended supply chain (Allen, 2001). It is more strategic in nature and requires greater skill sets than e-commerce due to the front-end back-end integration.

As an academic study, IS needs to educate students in the efficient and effective application of all components of an information system (computer hardware, software, data, procedures and people) to solve business and organisational problems. There have been a number of studies which have attempted to identify IS graduate skills and the resultant curriculum.

The IS'97 Model Curriculum (Davis et al, 1997) was a collaborative development between industry and academia. The model provided guidelines and resources to facilitate the development of quality undergraduate IS curriculum. Interestingly, this model curriculum, just five years old, makes little mention of electronic commerce or e-business. The recent revision to this model curriculum (IS, 2002) places far more importance on the role of e-commerce. The designers of the model curriculum have added the new subject "Electronic Business Strategy, Architecture and Design" (Davis et al 2001). However the course descriptions of the other courses in the model curriculum failed to realise the impact of the internet on all areas of the IS curriculum. Previously authors identified the shortcomings of the IS'97 Model in relation to enterprise resource planning systems (Hawking, Shackleton and Ramp, 2001)but again the impact was ignored in the revised model.

In an attempt to identify the IS skills relevant for the development and use of large information systems the American National Science Foundation (ISCC, 1999) sponsored a task force of both industry and academic participants. The skills were categorised into Personnel Skills, Interpersonal Skills and Technical Knowledge and Skills. However even though the document acknowledged the importance of enterprise wide systems, it made failed to recognise the extension of these types of systems into the e-business arena and the skill requirements to support this extension. The resultant Information Systems-Centric Curriculum Document (ISCC, 1999) recommended an inverted curriculum approach which allows students to experience and analyse real application systems from the beginning of their course (Lidtke et al, 1999). This requires students to take greater responsibility for their learning with academics taking on the roles of mentors. An essential recommendation was the ongoing collaboration with industry to enable meaningful project activities, site experiences, case studies, and assistance in updating the curriculum.

In 2000 the U.S. Departments of Commerce, Labour and Education released the 21st Century Skills report designed to identify skills required by students to work in the "digital age". The report identified a number of broad generic skills but made little reference to specific IT skills (Stuart, 1999).

The massive number of IT vacancies around the world, Australia 30,000 (Information Age, 1998), USA 200,000 and Germany 90,000 (The Australian, June 2000) have resulted in governments and industry conducting studies to identify the specific skill shortage areas (Stuart, 1999; British Computer Society, 1999).

The Deloitte (1999) report mapped E-skills into 9 super-types:

- Internet \& multimedia,

- Application development,

- Web development tools,

- Operating systems,

- Internetworking, 
- LAN administration,

- System software and support,

- Database management,

- Communications installation and maintenance.

The National Office of Information Economy reported that $37 \%$ of businesses identified lack of skills as a major barrier to business use of e-commerce (NOIE 2000).

The incorporation of e-business and related issues into university curriculum has been driven by a number of factors:

- Analyst's projections of the enormous growth in this market (Bermudez et al, 2000).

- Student's realisation of the potential lucrative job market.

- Industry looking for graduates with the appropriate skill set and

- Academics attempting to keep abreast of the current issues in the information technology industry.

The challenge for IS academics is to modify their curricula to embrace the concepts of e-business so as to provide graduates with the necessary skills to assist business enterprises in the future.

Many IS departments have spent much time and resources in modifying their curriculum to incorporate Enterprise Resource Planning Systems (ERP) (Hawking et al, 2001; Lederer-Antonucci, 1999; Watson and Schneider, 1999). These systems are seen as a tool to reinforce many of the IS concepts. To facilitate the inclusion of ERP systems into the curricula universities formed strategic alliances with the major ERP vendors (Hawking, 1999). The ERP vendor benefits from these alliances by increasing the supply of skilled graduates that can support their product thereby enhancing its marketability and lowering the cost of implementation while the university gains access to the software at a greatly reduced cost. One such alliance is the SAP University Alliance. Through these alliances, universities have made a commitment to incorporate ERP systems into their curriculum and have expended an enormous amount of effort and resources to achieve this. For many of these universities it is important to investigate how they can leverage their current level of expertise in ERP systems curriculum to incorporate many of the ERP e-business tools to support the teaching of e-business concepts. ERP systems are considered by many as essential component of any e-business strategy (PWC, 1999; Shephard and Boulanger, 2000). These systems include a broad range of functionality to support the various components of e-business.

This paper examines the potential use of one component of an ERP's e-business functionality, the OnLine Store as a tool to teach e-business concepts. The paper will focus on the SAP ERP system as they are the market leader and have the largest university partnering program in the Australasian region.

\section{SAP and e-Business}


Since SAP's R/3 Release 3.1, Internet-enable applications via the "inside-out" approach have been made available. The Internet applications are developed to add a web user interface to already existing SAP transactions. Since then SAP has offered increased e-functionality especially in its more recent release, mySAP. SAP is now touted as the platform for many companies' e-business strategy. Its various components support e-business through the intranet, business to consumer (B2C) and Business to Business (B2B) models. It does this from both a technical and business perspective. The relationships between these components can be summarised in the diagram below. (Figure 1)

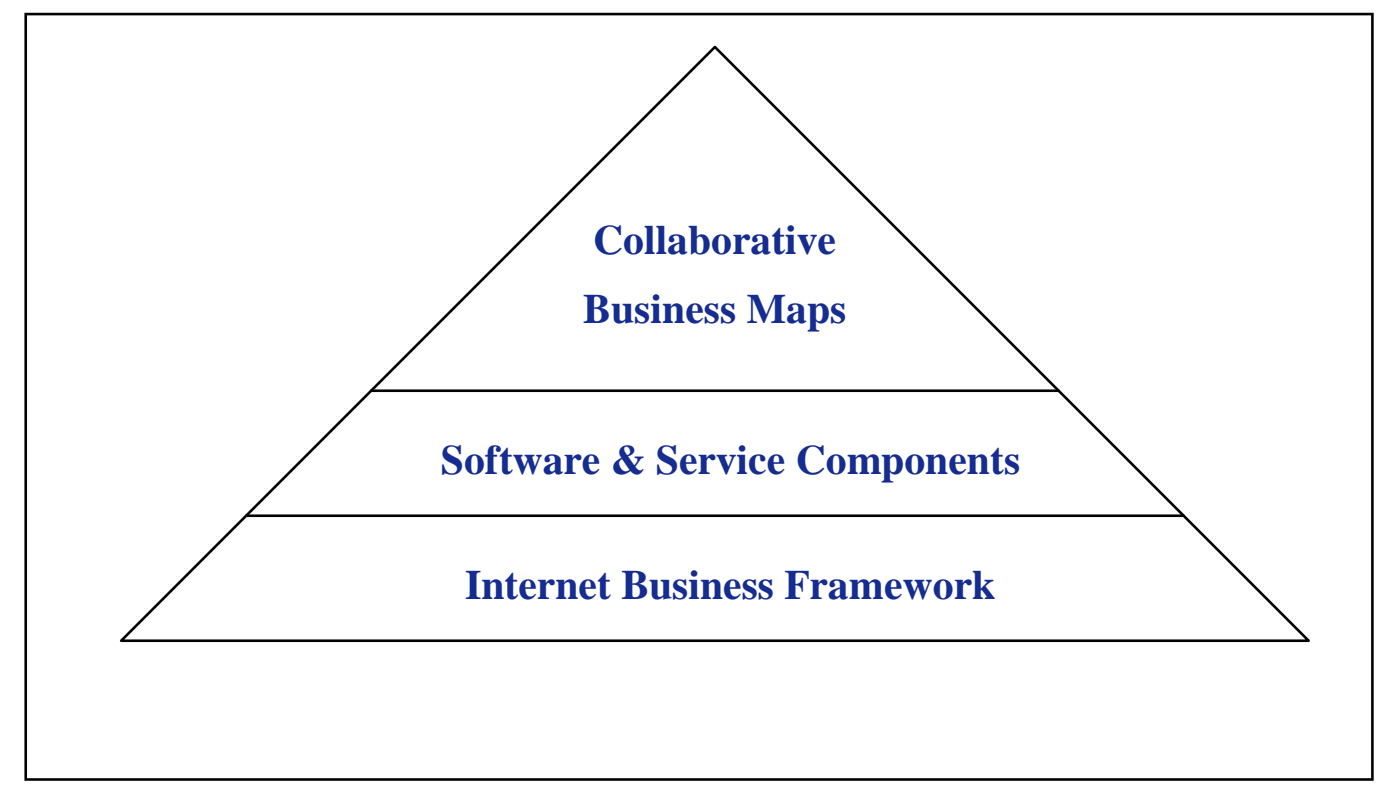

Figure 1. Relationships between SAP Components

\section{Internet Business Framework}

This framework has been developed to support the evolving nature of software and particularly ERP systems. It facilitates the introduction of new software modules that are incorporated in the ERP system or new components that must interact with the system. This includes non-SAP software that must interact with the ERP system. The Business Framework enables open, integrated, component-based enterprise business application solutions to be produced.

The Business Framework is based on a top down approach utilising the following components:

- Business Components. These are defined encapsulated business functions such as modules (Human Resources, Logistics, Financials) and functional software (Business Warehouse, Knowledge Management).

- Business Objects. An object-orientated approach is adopted to define the objects involved in a particular business process such as customer and invoice.

- Interfaces. These provide an open access to business components via standard access methods. This is achieved via BAPIs (Business Application Programming Interfaces), which are the methods or functions assigned to each business object. BAPIs act like interfaces for controlled method calls between SAP business objects and objects of external providers. BAPIs form the foundation of SAP's Internet strategy by providing an object-orientated interface between different business components.

- Integration Technology. SAP incorporates integration technology that supports industry standards such as CORBA, XML, COM+ and EDI to enable open access to SAP and non-SAP components. 


\section{Software and Service Components}

The software and services provided by SAP for e-business are primarily provided by Internet Application Components (IAC). Since SAP R/3 version 4, customers have been provided with more than 35 IAC's. An IAC defines a complete internet application consisting of a transaction from the ERP system and the corresponding HTML templates. Traditionally for a user to interact with SAP R/3 they required a reasonable level of training and expertise. This becomes a serious barrier when a company expects customers, potential clients, vendors, business partners and other employees to interact with the system as is the expectation with e-business. Through the use of IAC's, the HTML display is user-friendly and functional providing users with an easy-to-use interface.

IAC's can be broadly categorized into electronic retailing, customer service, purchasing, employee self service and internal services. The OnLine Store is an example of a supplied IAC. The Online Store is a business to consumer (B2C) solution provided to customers in a standard SAP system

\section{Collaborative Business Maps}

In an attempt to facilitate the transition of companies to an e-business environment, SAP has developed collaborative business maps. These maps define the activities, roles, system interfaces, and business documents required for business to business transactions using the ERP system. ERP vendors, in the past have argued that their systems include "best business practice" and this claim applies equally in the eworld.

The business maps provide three different views of how a company can establish, implement and evaluate their e-business strategy.

- The Interaction View illustrates to companies how their business processes interact with their business partners' processes from an e-commerce perspective. It outlines which users should be involved and what business documents are exchanged.

- The Component View provides information on which technical aspects need to be installed to support the level of interaction as defined in the previous view.

- The Collaboration Scorecard provides a methodology to assess the return on investment for the ecommerce strategy.

The Business Maps provide a company with the necessary tools to develop, implement and assess their ebusiness strategy from a B2B perspective.

\section{OnLine Store}

SAP's OnLine Store is one of the Internet Application Components (IAC) supplied with the system. The OnLine Store was first delivered with SAP R/3 release version 3.1G. This tool was designed for customers who wish to rapidly implemented a web-based selling solution that is integrated with the back-end system, SAP R/3. The application uses an "inside out" approach which means that even though the sales process occurs on the internet, all the logic, master data and configuration occurs in the SAP system. This provides companies with the advantage of not having to redesign their existing sales and distribution processes, settings and data which exist within the R/3 system.

SAP's OnLine Store has all the standard features of many online shopping facilities. Its electronic product catalogue interacts with SAP's sales and distribution module to display products, descriptions and prices. It has the capabilities to display images, sound files and specification documents. The online store incorporates the standard "shopping cart" functionality for the identifying of goods to be purchased. A customer is able to check the status of their orders placed via the internet or any other medium. The OnLine Store provides available-to-promise capabilities whereby a customer can specify the quantity of 
items required and the SAP system will indicate when the items will be available. The functionality exists for customers to use a variety of payment methods for the purchasing of the goods in the shopping cart and display the details of all their financial transactions.

The OnLine Store facility in SAP is a valuable educational tool for IS students and could form the basis of an e-business curriculum. The IS 2002 curriculum model incorporated a new course focussing on ebusiness. The details of this course are:

Scope This course examines the linkage of organizational strategy and electronic methods of delivering products, services and exchanges in inter-organizational, national, and global environments. Information technology strategy and technological solutions for enabling effective business processes within and between organizations in a global environment are considered.

Topics Electronic commerce economics, business models, value chain analysis, technology architectures for electronic business, supply chain management, consumer behavior within electronic environments, legal and ethical issues, information privacy and security, transborder dataflows, information accuracy and error handling, disaster planning and recovery, solution planning, implementation and rollout, site design, Internet standards and methods, design of solutions for Consumer Internets, Intranets and Extranets, EDI, payment systems, support for inbound and outbound logistics.

For students to comprehend the issues associated buying and selling over the internet they need to have an understanding of the major business processes involved in e-business. A major advantage of the SAP Online Store is back-end front-end integration. This enables students to familiarise themselves with the sales and distribution process and its associated master data. They follow the flow of data from the customer interaction via the web through to the SAP system and the responding data back to the customer. The Online store provides the opportunity to view the transaction from both a buyer's and seller's perspective. This end-to-end process is essential knowledge for any student required to understand webbased sales and purchasing.

An essential component of the OnLine store is the product catalogue. The catalogue displays the products available for sale over the web. Students can create their own products within the SAP R/3 system and then design a product catalogue to display their products via the Online Store. There are a number of decisions they would be required to make before the catalogue could be created. These include:

- Should the catalogue be used only for product presentation or should customers be able to make purchases via the catalogue?

- What details should be displayed on the web for each product?

- What format should these details take, length, images, sounds etc?

- Will customers be able to download detailed product specifications?

- Will the same price apply to all customers?

- How many languages will the product catalogue need to support? (SAP 2000)

To answer these questions students would need to understand the business models and strategies of their educational scenario the Online Store would be used to support. They would need to understand the various pricing options available via the catalogue.

- Will prices for products be cheaper via the web in comparison to other mediums?

- What shipping options are available and how do these affect pricing?

- What taxes are applicable? 
In business-to-business scenarios customers often access specific product catalogues based on their log on details. This reflects pricing agreements and decisions, and assists in enforcing business rules applied to predetermined customers. The OnLine Store product catalogue provides this level of functionality.

The OnLine Store adopts an "inside out" approach and therefore students would need to configure the SAP R/3 system to reflect their decisions in regard to the above questions.

Once the OnLine Store has been implemented students from within the university and around the world can use it as an example of buying over the web. They select products into the shopping cart, pay using fictitious credit card details and receive an email to indicate their purchases are on their way. They could logon under different company names to display company specific product catalogues. Students within the university could track the placement of online orders, sourcing, picking, billing, delivery and changes in inventory levels. They can explore the accounting documents that are generated with this type of transaction. From a business perspective they could produce a variety of reports to demonstrate the performance of their web based store.

From a technical point of view the OnLine Store is based on a three tier architecture which requires a web server, internet transaction server (ITS) and security functionality (firewalls) to be implemented. The ITS is used to map the SAP R/3 screens to a HTML format. It provides the necessary functional and performance characteristics required to execute $\mathrm{R} / 3$ transactions. The application logic remains within the $\mathrm{R} / 3$ system thereby providing an "inside-out" approach. Students can explore the Online Store's technical configuration to gain understanding of security issues and performance. The ITS administration tool can be used to provide security logs as well as monitoring performance.

The architecture of the ITS supports the rapid development of web user interfaces for existing transactions and comes with a PC-based development tool ready for HTML template development - SAP@Web Studio. This development tool is well suited to users who have little technical background and are looking for a simplified way to create web applications. It operates, for the most part, in off-line mode and requires almost no specific SAP knowledge. The newer version of SAP R/3 (4.6c) incorporates the Web Application Builder and has the advantages of an online development tool including repository access, reuse and navigation support. It allows for both the "inside-out" and the "outside-in" development styles that are used in building common web applications for SAP. Both these tools would enable students to modify the OnLine Store or create enhancements.

At Victoria University a group of post graduate ERP students, in consultation with an industry-based project management committee, are in the final stages of implementing the OnLine Store. Other than providing a practical experience for the students involved, the OnLine Store is intended to be used across the faculty of Business and Law as the basis for teaching e-business concepts. The Online Store implementation will be fully documented and made available to other universities to assist them in their curriculum development.

Depending upon which discipline area students are studying will determine the focus of curriculum development on the OnLine Store.

\section{Conclusion}

Many universities have struggled to incorporate ERP systems into their IS curriculum. They are now faced with the issue of how best to incorporate e-business. They often treat the two technologies separately without realising the synergy between the two. We have outlined how IS curriculum can be extended to include e-business using ERP systems functionality. The Online Store is a product which universities who are part of SAP's University Alliance Program have readily available to them.

Before a university decides to build upon their existing ERP knowledge and resources to teach e-business concepts and skills in an IS curriculum, consideration should be given to the following questions: 
Teaching E-Business Concepts

- How is electronic business covered in the IS curriculum at present?

- If electronic business issues are to be addressed, then in what ways and to what extent should this be done?

- How are ERP systems utilised in IS curriculum at present?

- Can our existing ERP resources be extended to support the teaching of e-business concepts and skills?

\section{References}

Bermudez J., Kraus B., O’Brien D., Parker B., and Lapide L., (2000) The Report On E-Commerce Applications, AMR Research

British Computer Society. (2000), The British Computer Society Review 2000: Computing in the $21^{\text {st }}$ century, located at WWw.bcs.org.uk/review/2000 accessed January 2002

Davis, G., et al., (1997), IS'97: Model Curriculum and Guidelines for Undergraduate Degree Programs in Information Systems, ACM and AITP: USA.

Deloitte, Touche, \& Tohmatsu, (1999), Future Demand for IT\&T Skills in Australia 1999-2004, IT\&T Skills Workforce, A Report Developed for the Australian Government, as reported in www.noie.com.au, accessed May 1999

Hawking, P. (1999), The Teaching Of Enterprise Resource Planning Systems (Sap R/3) In Australian Universities. Proceedings of the 9th Pan Pacific Conference, Fiji.

Hawking P., Shackleton P., Ramp A., (2001), "IS' 97 Model Curriculum and Enterprise Resource Planning Systems" Business Process Management Journal Vol. 7, No.3.

ISCC99 Information Systems Centric Curriculum located at http://Www.1scc.unomaha.eduaccessed on January 2002

Lederer-Antonucci Y., (1999), Enabling the business school curriculum with ERP software experiences of the SAP University Alliance, Proceedings of the IBSCA'99, Atlanta.

Lidtke, Doris K., Gordon E. Stokes, Jimmie Haines and Michael C. Mulder (eds), (1999), ISCC'99, An Information SystemsCentric Curriculum'99 Program Guidelines. URL hutp:/Www.Iscc.unomaha.eduaccessed March $20^{\text {th }} 2001$.

Longenecker, H.E.J., D. L. Feinstein, et al., (1994) "Information Systems '95: A Summary of the Collaborative IS Curriculum Specification of the Joint DPMA, ACM, AIS Task Force", Journal of Information Systems Education,. Winter: p. 174186.

NOIE 2000, (2000), The Current State of Play: Australia and the Information Economy located at http://wWw.noie.gov.au/projects/information_economy/research\&analysis/index.htm accessed January 2002

PWC, (1999), Electronic Business Outlook, PricewaterHouseCoppers located at ntp:/Www.pwcglobal.comaccesses May 2001.

Richards, R.M. and C.C. Sanford, (1992), An Evolutionary Change in the Information Systems Curriculum at the University of North Texas. Computers \& Education, 19(3): p. 219-228.

SAP, (2000) OnLine Store Made Easy: Accelerated Internet Selling, SAP Labs, Palo Alto.

Shephard J., and Boulanger D., (2000), Don't Let Your SAP Investment Atrophy, AMR Research as located at Www.amrresearch.com accessed January 2001.

Stuart, L., (1999), 21st Century Skills for 21st Century Jobs, US Department of Commerce, January 1999, as located at WWW.vpskillssummit.org, accessed August 2000.

Watson, E. and H. Schneider, (1999), Using ERP Systems in Education. Communication of the Association for Information Systems, 1(9).

\section{Biographies}

Paul Hawking is a lecturer in the School of Information Systems at Victoria University, Melbourne, Australia. He is the SAP Academic Program Director for the Faculty of Business and Law and is responsible 
for the facilitation of ERP education across the university. He has been involved in education delivery and curriculum development for the past twenty years and has co-authored a series of computer texts. He is currently Chairperson of the Australian SAP User Group.

Brendan McCarthy is also a lecturer in the School of Information Systems at Victoria University, Melbourne, Australia. He is the program co-ordinator of the Master of Business in Enterprise Resource Planning Systems. He has been involved in education delivery and curriculum development for the past twenty-five years and has co-authored of a series of computer texts.

Susan Foster is an Information Systems lecturer at UNITEC, Auckland, New Zealand. She is coordinator of the SAP University Alliance Program in her institution. Susan has been involved in education delivery and curriculum development for the past twenty years. Her research focuses on ERP systems and the impact they have on organisations. 